\title{
DICOM NETWORK IMPLEMENTATION AND USAGE IN THE CONTEXT OF THE COVID-19 PANDEMIC
}

\author{
Alexandr GOLUBEV1凶 \\ ${ }^{1}$ Research and Educational Networking Association of Moldova, Chisinau, Republic of Moldova \\ Received 10 Dec 2020, Accepted 03 Febr 2021 \\ hitps://doi.org/10.31688/ABMU.2021.56.1.10
}

\section{Abstract}

This article is targeted to show solutions based on the technical information technologies to help patients, medical professionals and institutions for using DICOM Network application in the context of special requirements during pandemic.

The objective of the study was to show how to minimize contacts with the patients by using telemedicine and online consultations based on the information technologies solutions.

Material and methods. The data used in this study are based on the DICOM Network informational system, that is targeted to collect medical images based on DICOM format. This system collects all type of DICOM investigations, including tomography investigations, X-Ray images, ultrasonography and others. The average flow of the data is about $10 \mathrm{~TB}$ per year. In this study, we used input data collected by this system from 4 medical institutions.

Results. There were defined the gaps in the existing software solutions for telemedicine. Based on the existing workflow analysis and urgent requirements of the medical institutions with COVID-19 patients, it was implemented a set of new modules and functionalities for existing DICOM Network

\section{Résumé}

Mise en œuvre et utilisation du réseau DICOM dans le contexte de la pandémie de COVID-19

Introduction. La pandémie de COVID-19 a découvert un certain nombre de problèmes dans le système médical mondial. Cet article vise à présenter des solutions basées sur les technologies de l'information technique pour aider les patients, les spécialistes et les institutions à utiliser l'application DICOM Network dans le contexte d'exigences particulières en cas de pandémie.

L'objectif de l'étude était de montrer comment minimiser les contacts avec les patients en utilisant la télémédecine et les consultations en ligne basées sur les solutions des technologies de l'information.

Matériel et méthodes. Les données utilisées dans cette étude sont basées sur le système d'information DICOM Network, qui vise à collecter des images médicales basées sur le format DICOM. Ce système recueille tous les types d'investigations DICOM, y compris ceux de tomographie, les images aux rayons $\mathrm{X}$, l'échographie et autres. Le flux moyen des données est d'environ $10 \mathrm{~TB}$ par an. Dans cette étude, nous avons utilisé des données d'entrée collectées par ce système auprès de 4 établissements médicaux. 
system to limit direct contacts with the patients and to reduce the costs of the imaging investigations.

Conclusions. All the DICOM Network changes were done in parallel with the spreading of the pandemic "on the fly", but all the functionalities were implemented in time and have helped, on one hand, to reduce the direct contact of physicians with the infected patients and, on the other hand, to reduce the costs for an investigation for about 2 EUR per investigations and 3000 EUR per month only for X-Ray investigations for COVID-19 patients.

Keywords: DICOM, COVID-19, e-health, mobile applications.

\section{Abbreviations:}

DICOM - Digital Imaging and Communications in Medicine

AI - Artificial Intelligence

PACS - Picture Archiving and Communication Systems

\section{INTRODUCTION}

The COVID-19 pandemic raised many problems for healthcare systems worldwide. SARS-CoV-2 spreads by air and the medical staff should be protected from infection by limiting the contact with COVID-19 patients. It is not possible to exclude the contact with the patients, but it is possible to minimize it by using telemedicine and online consultations. Digital Imaging and Communications in Medicine (DICOM) Network become a demanded tool for medical personnel in this period. In this article it is described step by step the evolution of DICOM Network during the pandemic and the best practices of using the system for online consultations, as well as implemented functionalities specific to pandemic period.

\section{RADIOLOGY ISSUES AND REQUIREMENTS IN THE CONTEXT OF COVID-19 PANDEMIC}

An important problem during the pandemic period in medical institutions is the direct contact limitation between medical staff and patients, as well as between infected patients and other patients. In all the medical institutions there were created isolated zones, so called "Red Zone", with a strict limited access, to avoid contact with infected patients. Medical personnel who works in these zones is protected with special equipment.
Résultats. Les lacunes des solutions logicielles existantes pour la télémédecine ont été définies. Sur la base de l'analyse du flux de travail existante et des exigences urgentes des institutions médicales avec des patients COVID-19, il a été mis en ouvre un ensemble de nouveaux modules et fonctionnalités pour le système DICOM Network existant afin de limiter les contacts directs avec les patients et de réduire les coûts des examens d'imagerie.

Conclusions. Tous les changements du réseau DICOM ont été effectués en parallèle avec la propagation de la pandémie "à la volée ", mais toutes les fonctionnalités ont été implémentées à temps et ont permis, d'un côté, de réduire le contact direct des médecins avec les patients infectés et de l'autre côté de réduire les coûts d'une investigation d'environ 2 EUR chacune et 3000 EUR par mois uniquement pour les examens radiographiques pour les patients COVID-19.

Mots-clés: DICOM, COVID-19, e-santé, applications mobiles.

The number of doctors in the "Red Zone" is limited and most of the examinations should be made outside this zone, without direct contact with the patient. Radiological investigations are necessary in COVID-19 patients. In most cases, the equipment is installed directly in the "Red Zone" and imaging specialists who work on this equipment are in the high-risk group.

But documents and pictures printed to analyze and make a consultation/decision should not be taken outside the "Red Zone", because they are potentially infected. However, these documents are required by the specialists who work outside the "Red Zone", in the same medical institution or outside, from home or in an external hospital (Fig. 1).

Based on government recommendations during pandemic, many employees are working from home. Specialists can help the colleagues who work in the hospitals only if they have online access to the medical images and tools to add consultations in electronic format. The same issue is actual for online consultations from another medical institution.

Other problem critical for hospitals is that the investigations should be repeated during hospitalization of the patients. The average number of investigations is $3-4$ per patient during hospitalization period. Archives and tools to compare the images and track the history of investigations are necessary. 


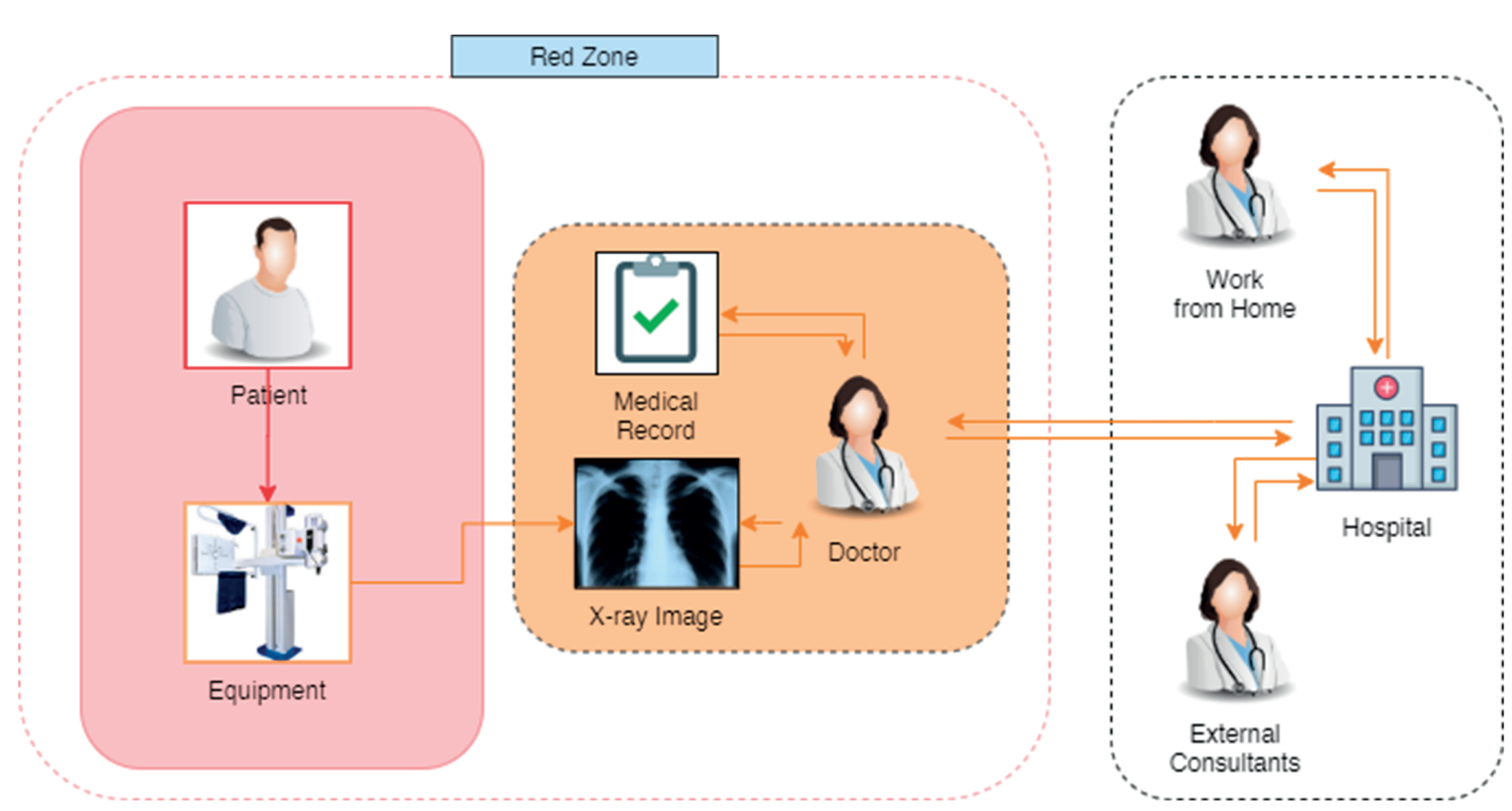

Fig. 1. Infected documents in the "Red Zone".

\section{Definition of Dicom Network}

DICOM is the standard for communication and management of medical imaging information and related data. DICOM is commonly used for storing and transmitting medical images, enabling the integration of medical imaging devices such as scanners, servers, workstations, printers, network hardware, and picture archiving and communication systems (PACS) from multiple manufacturers.

The DICOM Network project was launched in the Republic of Moldova in 2012. Its goal was to provide access to investigations for medical staff with the appropriate access rights, and for patients to their own radiological investigations. As a result of the project, eleven medical equipment were connected to the system. Today, the system collects and processes more than 1TB of data per month.

The system has Data Storage and Data Processing components, distributed between different processing units and storages, which could be customized using specific interfaces. The system structure comprises the following data servers and modules:

- Data from equipment are collected in the "DICOM Server" modules, that can be installed in the same location with the medical equipment or can be distributed through other institutions and even cities or countries.

- All the investigations (DICOM Images) are archived on DICOM Servers, but the information about investigation is stored in DICOM Portal (like www.dicom.md) database. Various DICOM services are connected to one DICOM Portal.

- DICOM Portal stores all data, like user's info, access info, system settings, DICOM Server settings and some other, but not DICOM images. Each institution can deploy DICOM Portal internally using its own server.

- DICOM DATA Interface collects information about users and investigations from all DICOM Portals and provides functionality for data exchange and unification.

The general architecture of the DICOM Network system is presented in Fig. 2.

This system covers all necessary workflows for processing and documentation of medical investigations - from collecting images directly from equipment to archiving investigations in the patient's medical record. DICOM Network offers extended functionality for enhancing the quality of medical management and secured access to investigations. This helps medical specialists and patients to gain access to a structured database of medical images. At institutional level, the system is useful to reduce the costs of investigations and enhance the quality of provided services.

DICOM Network is already launched in production and can be accessed at the link http://www. dicom.md/. The system initially was deployed at the National Centre of Ambulance of Moldova and during the first year of functioning it has shown its utility and effectiveness: 


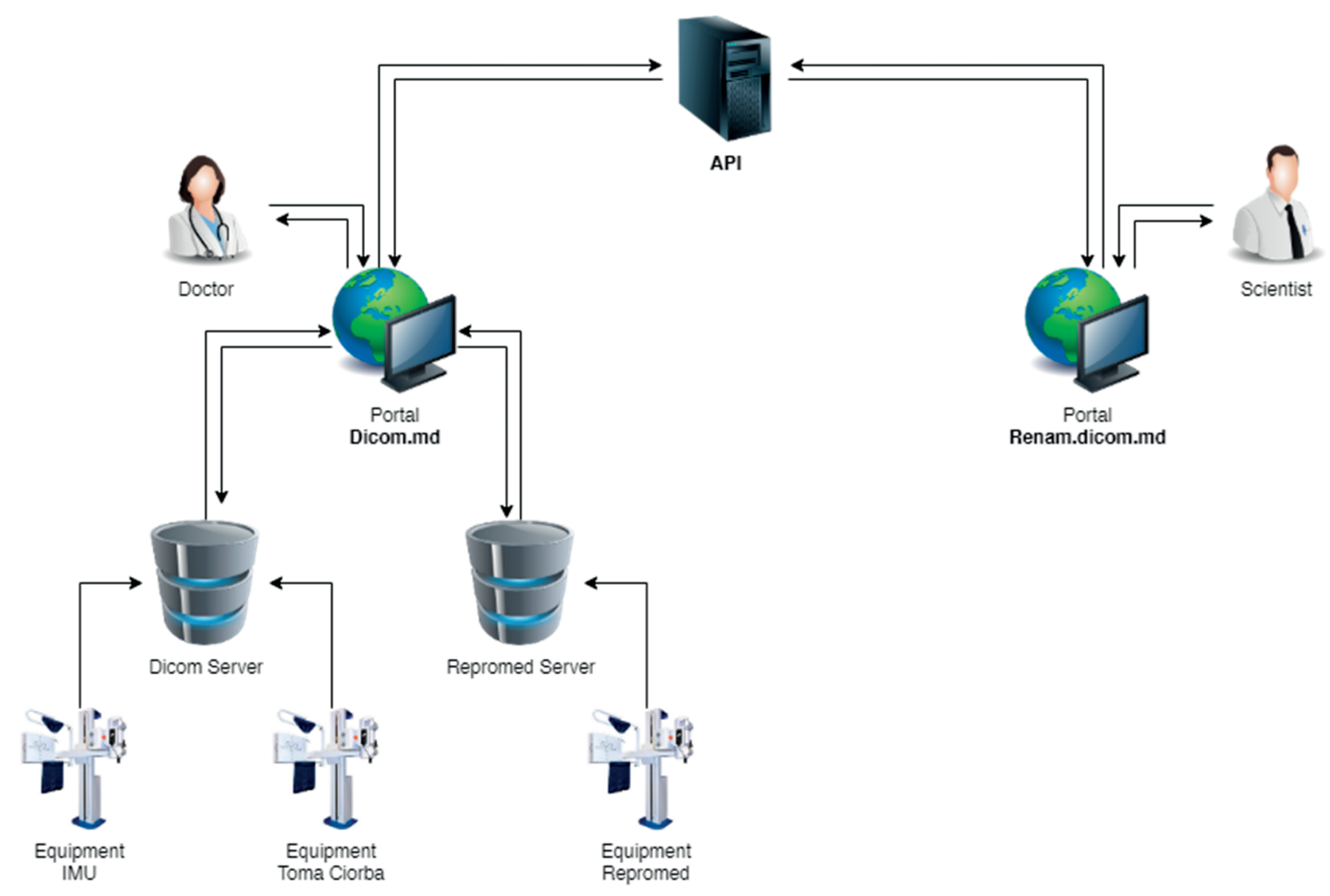

Fig. 2. General scheme of DICOM Network architecture.

- 2 DICOM Portals were set up: http://dicom.md/ national portal for Moldavian community and http://renam.dicom.md/ for research community.

- 3 DICOM Servers were installed.

- 4 hospitals were connected.

- 11 types of medical equipment were connected to the DICOM Network.

- 16 medical doctors from radiology used DICOM Network system in 24/7 regimen.

- About 250 investigations per day were collected by the system.

- Over 700 doctors had access to their patients' investigations from their working place.

During the pandemic period, the DICOM

Network system was installed in 3 new hospitals, from which 2 hospitals were entirely COVID-19 dedicated. Based on statistics, the number and percentage of investigations for COVID-19 grew every month starting from April 2020 (Fig. 3).

DICOM Network system saved 16,000 EUR for COVID-19 investigations during 6 months and this value increases every month.

\section{IMPLEMENTATION OF DICOM NETWORK FOR ONLINE CONSULTATIONS}

In the period before COVID-19 pandemic, the DICOM Network online consultation module was not wide used by the doctors. In most cases, the specialists who worked with the equipment added data that were used by doctors in medical clinics.

During the pandemic period, when doctors started to work from home, to reduce the risk of infection by direct contact with the patients, online consultation tools become more demanded. This way, only one person (not necessarily a medical specialist) contacted the patient to acquire the image, and the specialist who had access to investigations from a safe zone or from home could make the decision in real-time (Fig. 4). The other feature that was welcomed is the reduced paperwork or completely excluding paper-based medical record, as paper could be a source of infection with SARS-CoV-2.

One functionality useful and necessary was the possibility of data exchange with another hospital. One of the first problems when pandemic started was that the X-Ray equipment from the Infectious Diseases Hospital "Toma Ciorba”, Chisinau (Republic of Moldova), was outdated and insufficient for the high flow of the patients. The emergency hospitals from Chisinau shared only the medical equipment with the Infectious Diseases Hospital "Toma Ciorba", but no specialists and software. The following problems appeared: 
8000

7000

6000

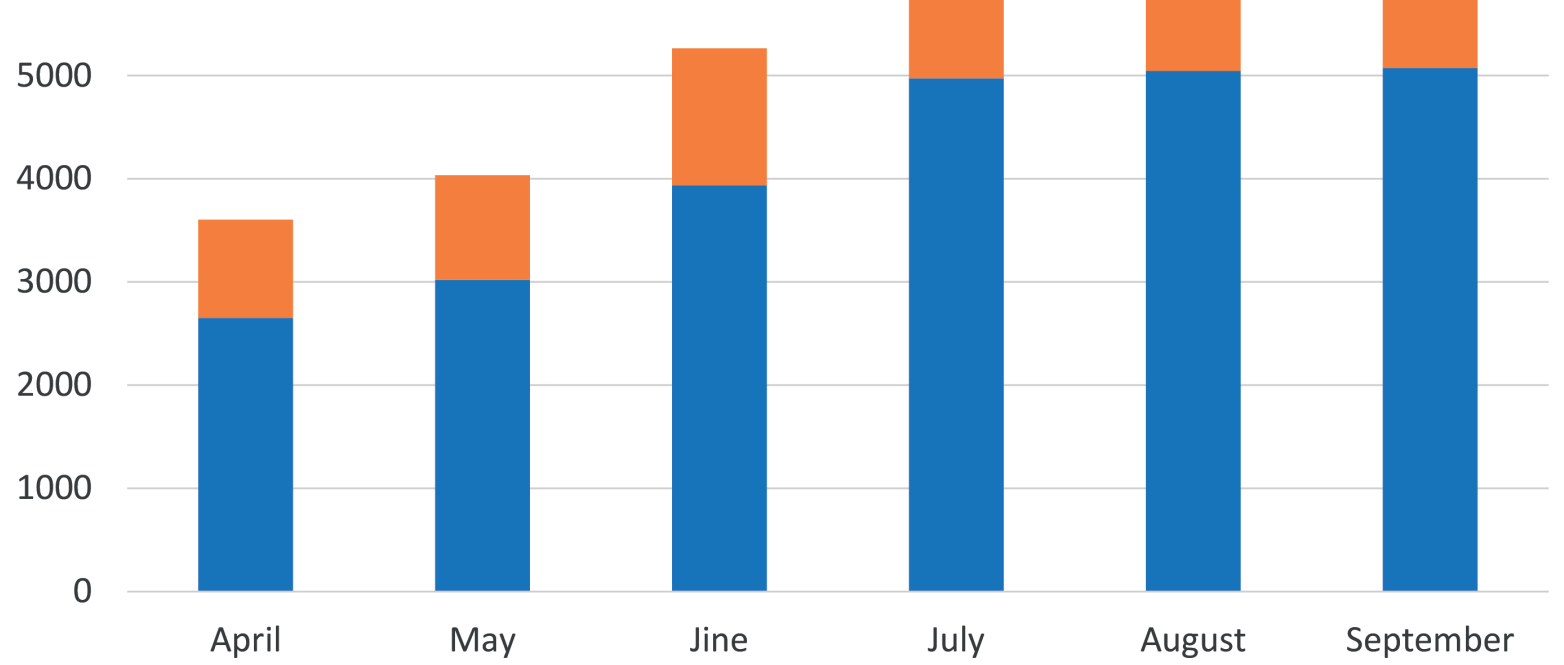

Fig. 3. Percentage of COVID-19 patients in the DICOM NETWORK system. Blue is non COVID-19 investigations and Orange are COVID-19 investigations.

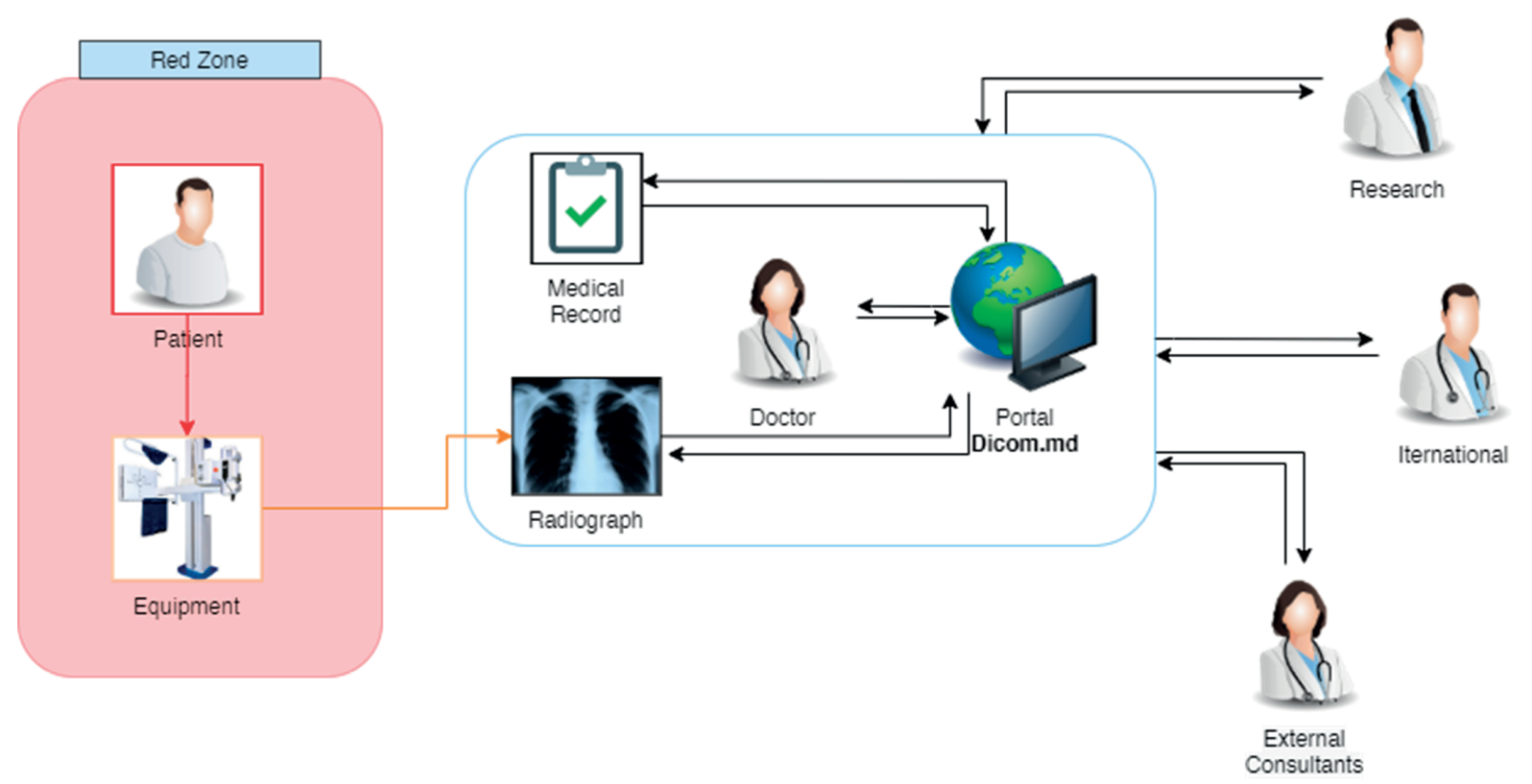

Fig. 4. Exclusion of direct contacts with infected patient.

- The specialists from the Infectious Disease Hospital "Toma Ciorba" needed help and assistance in many cases.

- The specialists from emergency hospitals were not allowed to enter in the Infectious Diseases Hospital.
- Because the Infectious Diseases Hospital never had this equipment before, it does not have the required infrastructure.

The DICOM Network system was used to solve these issues. All the equipment was connected to the DICOM Server in urgent mode. Because the Infectious Diseases Hospital did not have servers that could be used in the system, all the investigations 


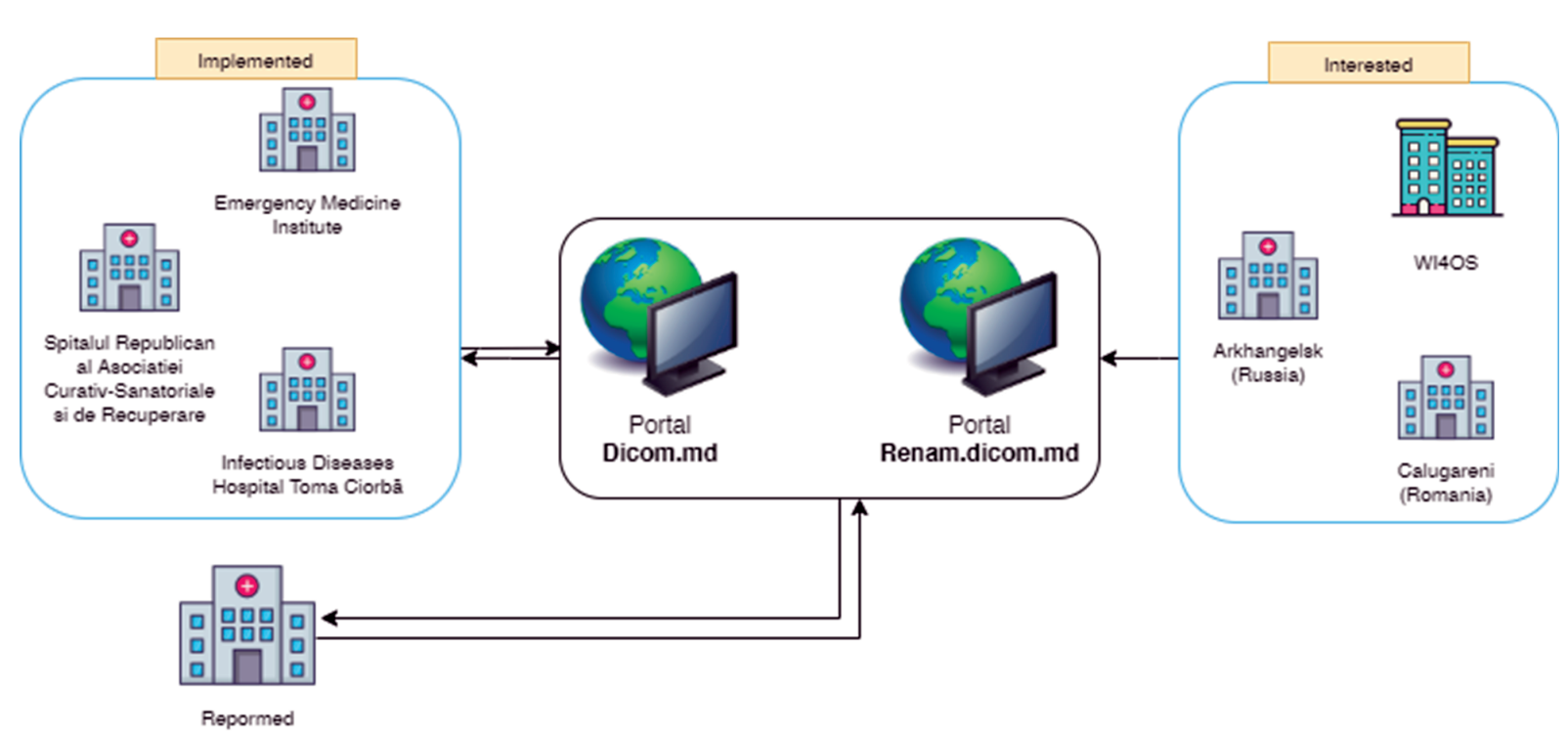

Fig. 5. DICOM Network installations and interest express.

were sent directly to the Emergency Institute of Chisinau, using a high-speed internet network. One of the most welcome functions was the X-Ray investigation archive that was not accessible before. In a few days, it was installed a specialized laboratory that used the DICOM Network and protected the medical specialists during the COVID-19 pandemic.

Nowadays, the system is installed in both public and private medical clinics in the Republic of Moldova and some institutions outside the country expressed their interest of using this system for medical and research/educational purposes (Fig. 5).

DICOM Network could be used for online consultations and secure data transfer, as well as for internal data sharing inside the institutions:

- In-hospital: to transfer the images from imaging departments to clinical departments.

- Regional level: the imaging investigations are performed in a specialized diagnostic center and sent to the hospital where the patient will be examined.

- International level: when the patient requests to send his imaging data abroad, for consultation by foreign specialists.

\section{Artificial intelligence and deEP learning as A SOLUTION FOR DATA ANALYSES AND CLASSIFICATION}

During pandemic, there were collected a large dataset of X-Ray investigations from patients with COVID-19. All these investigations were added to a specialized database and could be used for further research using artificial intelligence algorithms.

There are data enrichments that will be implemented using machine learning:
- Classifications - for each case (medical test $\backslash$ examination) it should be defined a rank, class, category. During the first phase, this will be done by the specialist and simple calculations. This will make the system "learn" how to categorize the data and make possible classifications without human actions.

- Precedent prediction - based on data collected before, the system should be able to find previous cases and make a preliminary decision, such as set priority, select the best specialists, show patient's record history for patients with the same issues.

- Novelty detection - it will try to define if a particular case is completely new (possibly a medical anomaly), that will make it rank as a high priority.

- Building rank dependencies - a set of data manipulations that should build the dependencies and help "system-learning". Some of dependencies should be built manually on start. Fig. 6.

The process of data enrichment is presented in

The Big Data processor will collect the data and make it "readable" for Artificial Intelligence processor. The Artificial Intelligence processor based on machine learning will work with the data and enrich it by information that will make possible to take a decision.

The project proposal focused on studying and finding solutions for optimizing the development of three aspects of medical examinations systems that determine their effectiveness: performance, data archiving and high-level of data security. The most suitable solution is the integration of distributed system components and usage of distributed computing resources and artificial intelligence algorithms. This 


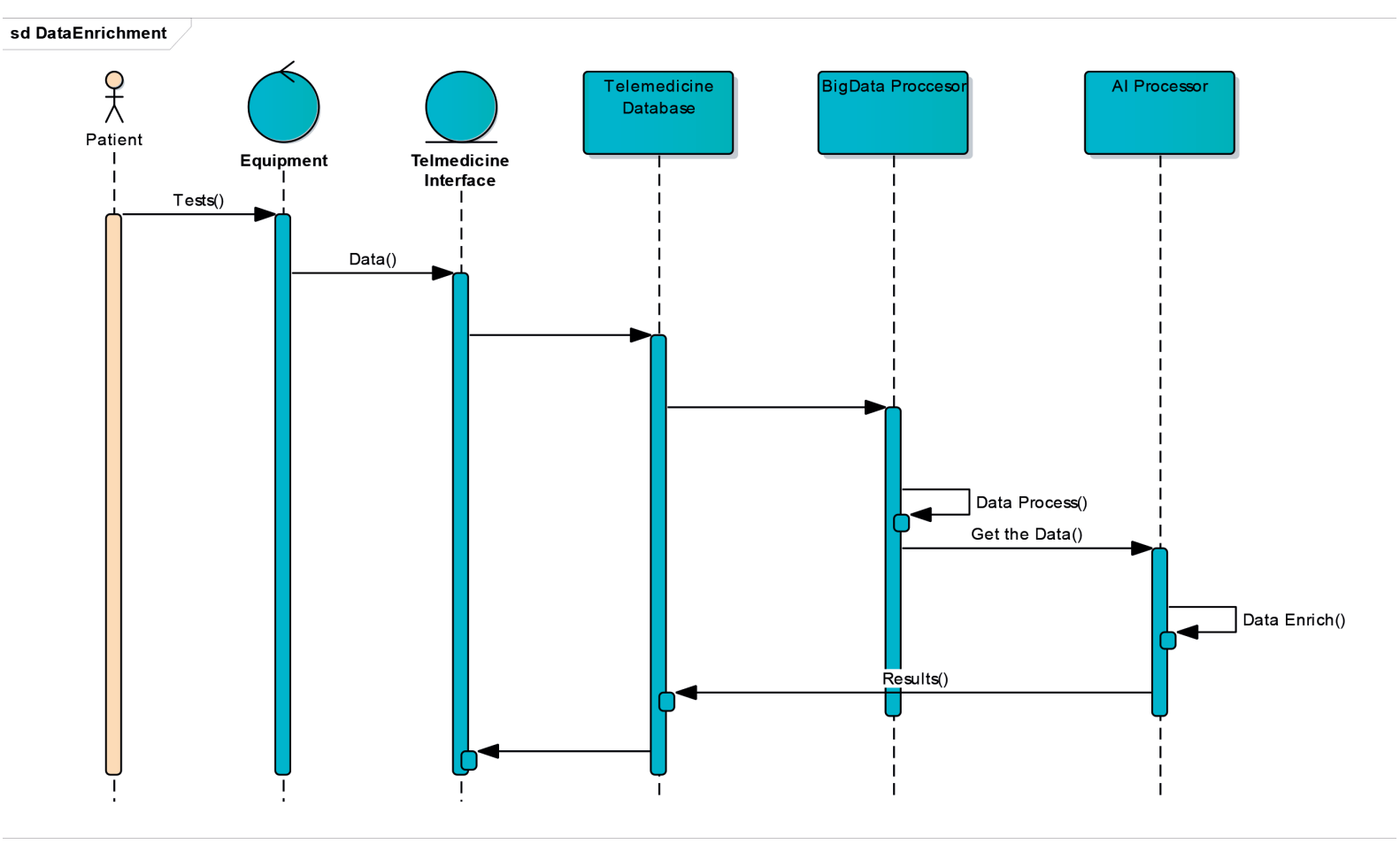

Fig. 6. Data enrichment DICOM Network.

innovative approach would have a significant impact, allowing to set up intellectual algorithms for searching similar cases in previous investigations and to accelerate the decision process of medical specialists.

Based on the collected data, it is planned to implement a specialized portal with statistical data, that will be useful to research and educational purposes.

\section{Conclusions}

The important application of DICOM Network integration for COVID-19 patients is the possibility of the online consultation of imaging data by medical specialists in complete isolation from any contact with infected patients or documents. This was achieved by specific systems customizations, that were possible due to flexible modular architecture and a good development team. As a result, the system was successful in various medical institutions and helped the national medical system during the pandemic in the Republic of Moldova.

The modern technologies integrated in the DICOM Network made possible to connect hospitals and equipment in short time, making possible to build a well-balanced structure for imaging departments in the "Red Zones" and save funds for hospital budget.

Each year, more and more medical institutions require additional resources for data archiving and new effective mechanisms for processing the collected medical images. It seems reasonable that more hospitals will become connected to the DICOM Network. The main problem is that many Moldavian hospitals do not have reliable server infrastructure and IT specialists to maintain this system inside the institution. This creates the necessity to allow these institutions to join DICOM Network that is hosted outside the internal network and ensure that personal data are not be shared outside. Cloud-based DICOM Network could be installed, that can be used for integration of new customers. The installation of DICOM Network in Cloud can make it more accessible to scientific communities, for research and educational purposes.

\section{Author Contributions:}

A.G. conceived the original draft preparation and was responsible for conception and design of the review. A.G. agreed with the final version of the manuscript.

\section{Compliance with Ethics Requirements:}

"The author declares no conflict of interest regarding this article"

"No funding for this study"

\section{Acknowledgements:}

None 


\section{References}

1. DICOM format description - http://dicom.nema.org/standard.html

2. Golubev A, Bogatencov P, Secrieru G, Iliuha N. DICOM Network - Solution for Medical Imagistic Investigations Exchange. International Workshop on Intelligent Information Systems. Proceedings IIS. 13-14 September, Chisinau, IMI ASM, 2011, pp. 179-182. ISBN 978-9975-4237-0-0

3. Trejo AC, Treuille SD, Alcántara IC. Implementing an integrated large-scale clinical information system for ISSSTE's Hospital Network in Mexico. SN Comprehensive Clinical Medicine. 2021;1-10.

4. Wadali JS, Sood SP, Kaushish R, et al. Evaluation of free, open-source, web-based DICOM viewers for the Indian National Telemedicine Service (eSanjeevani). Journal of Digital Imaging. 2020;33:1499-1513.

5. Strasser T, Wagner S, Zrenner E. Review of the application of the open-source software CilOCT for semi-automatic segmentation and analysis of the ciliary muscle in OCT images. PLOS ONE. 2020;15. e0234330.

6. Yuan J, Wu W, Zhang W, Lv X, Chen C. Design and implementation of a desensitization method of CT medical image based on DICOM. Journal of Physics: Conference Series. 2020;1576:012014.

7. Haripriya P, Porkodi R. Parallel deep convolutional neural network for content based medical image retrieval. Journal of Ambient Intelligence and Humanized Computing. 2020; DOI 10.1007/s12652-020-02077-w.

8. Bogatencov P, Secrieru G, Golubev A. DICOM data processing optimization in medical information systems. Networking in Education and Research, Scalable Computing: Practice and Experience. 2018;19(2):189-20.

9. Heo M-S, Kim J-E, Hwang J-J, et al. Artificial intelligence in oral and maxillofacial radiology: what is currently possible?. Dentomaxillofacial Radiology. 2020;20200375.

10. Juszczyk J, Badura P, Czajkowska J, et al. Automated size-specific dose estimates using deep learning image processing. Medical Image Analysis. 2020;68:101898.

11. Meenatchi RR, Shanmugavadivu P. A survey of medical imaging, storage and transfer techniques. In:Pandian D, Fernando X, Baig Z, Shi F (eds). Proceedings of the International Conference on ISMAC in Computational Vision and Bio-Engineering 2018. (ISMAC-CVB). ISMAC 2018. Lecture Notes in Computational Vision and Biomechanics, vol. 30, Springer, Cham.

12. Trivedi DN, Shah ND, Kothari AM, Thanki RM. DICOM® medical image standard. In: Dental Image Processing for Human Identification. Springer, Cham. 2019; https://doi. org/10.1007/978-3-319-99471-0_4.

13. Janakiraman S, Rajagopalan S, Amirtharajan R. Reliable medical image communication in healthcare IoT: watermark for authentication. Medical Data Security for Bioengineers, edited by Singh B, et al. ICI Global. 2019, pp. 1-26. http://doi: 10.4018/978-1-5225-7952-6.ch001.

14. Navamani TM, Bharadwaj A, Agrawal R, Agarwal U. Secure transmission of DICOM images by comparing different cryptographic algorithms. Materials Today: Proceedings. 2019;15(2). A1-A11.

15. dos Santos MR, Silva LB, Silva A, Rocha NP. DICOM metadata analysis for population studies. International Journal of E-Health and Medical Communications. 2019;10(1):1-17. 